\title{
PULSE SPRAY GAS METAL ARC WELDING OF ADVANCED HIGH STRENGTH S650MC AUTOMOTIVE STEEL
}

\author{
Ashok Kumar Srivastava *, Pradip K Patra \\ Centre of Excellence in Steel Technology, CSTPD, Department of Metallurgical \\ Engineering, OP Jindal University, Raigarh-496109, Chhattisgarh, India.
}

Received 07.07.2021

Accepted 28.11.2021

\begin{abstract}
With an increasing demand for safer and greener vehicles, mild steel and high strength steel are being replaced by much stronger advanced high strength steels of thinner gauges. However, the welding process of advanced high strength steels is not developed at the same pace. The performance of these welded automotive structural components depends largely on the external and internal quality of weldment. Gas metal arc welding (GMAW) is one of the most common methods used in the automotive industry to join car body parts of dissimilar high strength steels. It is also recognized for its versatility and speed. In this work, after a review of GMAW process and issues in welding of advanced high strength steels, a welding experiment is carried out with varying heat input by using spray and pulse-spray transfer GMAW method with filler wires of three different strength levels. The experiment results, including macromicrostructure, mechanical properties, and microhardness of weld samples, are investigated in detail. Very good weldability of S650MC is demonstrated through the weld joint efficiency $>90 \%$; no crack in bending of weld joints, or fracture of tensile test sample within weld joint or heat affected zone (HAZ), or softening of the HAZ. Pulse spray is superior because of thinner HAZ width and finer microstructure on account of lower heat input. The impact of filler wire strength on weldability is insignificant. However, high strength filler wire (ER100SG) may be chosen as per standard welding practice of matching strength.
\end{abstract}

Keywords: advanced high strength steels; S650MC; GMAW; pulse spray; microstructure.

${ }^{*}$ Corresponding author: Ashok Kumar Srivastava, ashok.srivastava@opju.ac.in 


\section{Introduction}

India has become a favored destination for setting up auto industries by global players over the last few years. As the Indian economy is open for global investment and global competition with open market policy, substantial foreign direct investment is being made by the Japanese, Koreans, Europeans and American OEMs. Many joint ventures have been set up with international auto majors. Consequently, most of the latest models of vehicles are getting manufactured in India. To fulfil global standard requirements of fuel economy and passenger safety, such vehicles need advanced high strength steels (AHSS) steel. The automotive industry is viewed as a 'locomotive of growth'. India is progressing to become the world's 3rd largest automobile market [1]. Vehicle safety needs a stronger body, which can be made with thicker steel (higher weight). On the other hand, fuel economy and environmental protection demand require a lighter vehicle. Both can be achieved by using steel with very high strength [2]. But the higher is the strength; the lower is the formability and weldability of conventional HSS. AHSS has a unique combination of good formability and weldability along with very high strength [3]. In the past, AHSS was defined based on strength only, such as YS > $550 \mathrm{MPa}$. However, now the characteristic microstructure is also a part of the definition. Microstructure of AHSS, consisting ferrite phase (soft), Bainite, martensite, fine precipitates and retained austenite (hard phases) leads to a favorable combination of strength and elongation [4-7]. Such microstructures enable good weldability in combination with high strength and toughness [8]. Due to the above-mentioned characteristics, demand for AHSS has increased dramatically during the past several years. Although production of S650MC with YS $>650$ $\mathrm{MPa}$ and $\% \mathrm{El}=20$ has started in India, its weldability aspects are not yet fully explored.

The automotive manufacturing process includes blanking, forming, piercing, welding, etc. Welding remains to be a fundamental contributor in manufacturing. It may control the overall productivity and quality of the product to a great extent. Gas metal arc welding (GMAW) is often employed where part geometry prevents the use of resistance spot welding (RSW) or when the design requires additional joint strength and stiffness, such as the long and cross member joining application. In general, GMAW is preferred for automotive applications [9]. To use AHSS effectively, it is important for designers and manufacturing engineers to understand the factors that may affect the performance of GMA-welded structures. The heat input of the welding process significantly affects the mechanical property of the heat-affected zone [HAZ] by its softening [10]. This can be controlled by varying the heat input by changing the metal transfer mode or the welding wire type. For example, in spray transfer mode, the welding current is relatively high leading to high heat input. Whereas in pulse spray transfer mode, the average current is low, leading to low heat input $[11,12]$. Welding filler wire also has an influence on joint strength.

However, the effects of various GMAW parameters on the weldability and tensile properties of S650MC are limited in the literature. Mechanical performance being highly structurally sensitive, various factors need to be considered before estimating the expected life of the component. Effect of base metal, soundness of weld joint, weld microstructure, stress distribution, and presence of any kind of notch needs to be considered for ensuring a good life for the component. Good weldability with low carbon equivalent (Ceq) and an established welding procedure is desired for such applications. Steel with a carbon equivalent of less than 0.41 is considered weldable [13]. 
Gas metal arc welding is one of the most common methods used in the automotive industry to join car body parts of dissimilar high strength steels. The performance of these welded automotive structural components depends largely on the external and internal quality of weldment. However, the welding process of AHSS is not developed at the same pace, and the availability of literature is limited. In this article, an overview of the influence of welding parameters and filler material on changes in the heat-affected zone of welded joints has been discussed. The welding experiment has been carried out with a variety of heat input by using the spray and pulse-spray transfer GMAW method. Three types of filler wires have been used with different strength levels. Mechanical properties, microstructure and micro hardness profile, have been estimated to get an in depth understanding of various structural features of the weld microstructure. The welded component manufactured with the developed steel is found suitable to use in automotive structural application.

\section{Experimental Methods}

\section{Materials}

The chemical compositions of the base metal and the filler metal are outlined in Table 1. Mechanical properties of the base steel and filler wire are shown in Table 2. The base metal is a $7.0 \mathrm{~mm}$ thick HR sheet of the newly developed EN 10149-2 S650MC Grade of AHSS. The Ceq of base metal has been calculated (Ceq $=0.37$ ) with the help of equation 1, formulated by the International Institute of Welding (IIW):

$$
\mathrm{Ceq}=[\mathrm{C}+\mathrm{Mn} / 6+\mathrm{Cu}+\mathrm{Ni} / 15+(\mathrm{Cr}+\mathrm{V}+\mathrm{Mo}) / 5]
$$

\section{Welding experiment}

The sheets were cut to $300 \mathrm{~mm} \times 150 \mathrm{~mm}$ size for welding into butt joint configuration with a single side $\mathrm{V}$ - groove with an angle of $70^{\circ}$ as shown in Figure 1(a). A gap of $\sim 1 \mathrm{~mm}$ was maintained in between two sheets for full penetration of the weld metal and good bonding between the two sheets. Three different standard filler wires (ER70S-6, ER80S-G and ER100S-G) were used in this work.

Table 1. Chemical composition of base metal and filler metal.

\begin{tabular}{|c|c|c|c|c|c|c|c|c|c|c|}
\hline \multicolumn{11}{|c|}{ Base Metal } \\
\hline$\% \mathrm{C}$ & $\% \mathrm{Mn}$ & $\% \mathrm{Si}$ & $\% \mathrm{~S}$ & $\% \mathrm{P}$ & $\% \mathrm{Ti}$ & $\% \mathrm{Al}$ & $\% \mathrm{Nb}$ & $\mathrm{N}$ & $\% \mathrm{Cr}$ & $\mathrm{C}$ eq \\
\hline 0.05 & 1.6 & 0.3 & 0.01 & 0.02 & 0.15 & 0.03 & 0.07 & 65 & 0.25 & 0.37 \\
\hline \multicolumn{11}{|c|}{ Filler Metal } \\
\hline \multicolumn{2}{|c|}{ Filler Wire Type } & $\% \mathrm{C}$ & $\% \mathrm{Mn}$ & $\% \mathrm{Si}$ & $\% \mathrm{~S}$ & $\% \mathrm{P}$ & $\% \mathrm{Cr}$ & $\% \mathrm{Mo}$ & $\% \mathrm{Cu}$ & $\mathrm{Ni}$ \\
\hline \multicolumn{2}{|c|}{ Type 1- ER70S-6 } & 0.1 & 1.5 & 0.9 & - & - & - & - & - & - \\
\hline \multicolumn{2}{|c|}{ Type 2- ER80S-G } & 0.1 & 1.4 & 0.8 & 0.03 & - & & - & 0.4 & 0.8 \\
\hline \multicolumn{2}{|c|}{ Type 3- ER100SG } & 0.1 & 1.1 & 0.5 & - & - & 0.5 & 0.2 & - & 0.5 \\
\hline
\end{tabular}


Table 2. Mechanical properties of the base steel and filler wire.

\begin{tabular}{llll}
\hline Materials & YS (MPa) & UTS (MPa) & $\%$ El \\
\hline Base Metal & 680 & 750 & 20 \\
Type 1- ER70S-6 & 470 & 560 & 26 \\
Type 2- ER80S-G & 540 & 625 & 26 \\
Type 3- ER100SG & 690 & 770 & 20 \\
\hline
\end{tabular}

All the wires are about $1.2 \mathrm{~mm}$ in diameter. The welding was carried out under a gas mixture shielding of $92 \% \mathrm{Ar}$ and $8 \% \mathrm{CO}_{2}$ with a flow rate of $15 \mathrm{~L} / \mathrm{min}$ using $1.2 \mathrm{~mm}$ diameter filler wire with direct current electrode positive (DCEP) in all welding experiments. The stick out distance from the electrode tip to base metal was maintained at $12 \mathrm{~mm}$ for getting a stable arc. The welding torch was set at an angle of $20^{\circ}$ in the welding direction and $20^{\circ}$ with the edge (joining face) of the sheets. Welding was carried out transverse to the rolling direction. Two different metal transfer modes, such as spray transfer (designated as S (S1, S2, S3)) and pulse spray transfer mode (designated as $\mathrm{P}$ (P1, P2, P3)), were used for comparison purposes. Sample subscript no. 1, $2 \& 3$ denote for filler wire type 1,2, and 3, respectively.

The high strength in AHSS is achieved by developing its microstructure by thermo mechanically controlled process (TMCP). Hence the microstructure may change as a result of heat input during welding [5]. Weld heat input is consequently a critical issue significantly affecting the strength and properties of the joint. If the heat input is too low, there is an increased risk of lack of fusion, and if the heat input is too high, the heat affected zone gets too big, which can cause detrimental effects within the weld. Heat input is also a very important variable governing the cooling time (the higher the heat input, the slower the cooling rate), which has a key role in the phase balance and mechanical properties of the HAZ and weld [14]. The same heat input was used for all three wires to nullify the effect of heat input and to establish the effect of filler wire on joint properties. The heat input has been calculated by using the following equation (2) [15]:

$Q(\mathrm{~kJ} / \mathrm{mm})=(I . V . \eta .60) /(W S .1000)$

Table 3. Process parameter for Spray continuous and pulse spray mode of metal transfer.

\begin{tabular}{|c|c|c|c|c|c|c|c|c|c|}
\hline \multicolumn{10}{|c|}{ Spray mode continuous } \\
\hline \multicolumn{2}{|l|}{ S No } & \multicolumn{2}{|c|}{ I (amp) } & $\mathrm{V}$ (volt) & \multicolumn{2}{|c|}{$\mathrm{WS}(\mathrm{mm} / \mathrm{min})$} & $\begin{array}{l}\text { WFS } \\
(\mathrm{m} / \mathrm{min})\end{array}$ & \multicolumn{2}{|l|}{$\mathrm{Q}(\mathrm{kJ} / \mathrm{mm})$} \\
\hline $\mathrm{S} 1, \mathrm{~S} 2, \mathrm{~S} 3$ & & 295 & & 29 & 300 & & 9.5 & 1.4 & \\
\hline \multicolumn{10}{|c|}{ Pulse spray mode } \\
\hline \multirow[t]{2}{*}{ S. N. } & \multicolumn{2}{|c|}{$\begin{array}{l}\text { Peak } \\
\text { Current/Time }\end{array}$} & $\begin{array}{l}\text { Base } \\
\text { Current }\end{array}$ & Time & $\mathrm{I}_{\mathrm{a}}(\mathrm{amp})$ & $\mathrm{V}$ (volt) & WS & WFS & $\begin{array}{l}\mathrm{Q} \\
(\mathrm{kJ} / \mathrm{mm})\end{array}$ \\
\hline & $\begin{array}{ll}\mathrm{I}_{\mathrm{p}} & \mathrm{T}_{\mathrm{p}} \\
\text { (amp) }\end{array}$ & (ms) & $\mathrm{Ib}_{\mathrm{b}}(\mathrm{amp})$ & $\mathrm{T}_{\mathrm{b}}(\mathrm{ms})$ & 1a (aimp) & V (voli) & $(\mathrm{mm} / \mathrm{min})$ & $(\mathrm{m} / \mathrm{min})$ & \\
\hline $\begin{array}{l}\text { P1, } \mathrm{P} 2, \\
\text { P3 }\end{array}$ & $364 \quad 14$ & & 150 & 10 & 275 & 24 & 300 & 9.5 & 1.05 \\
\hline
\end{tabular}

Here, I and $\mathrm{V}$ are the applied current and voltage, $\eta$ is the heat thermal efficiency, WS and WFS are the welding speed and wire feed speed. The welding parameters for 
both spray transfer mode and pulse spray transfer mode are listed in Table 3. All measuring instruments and testing equipment had valid calibration certificates with measurement of uncertainty within acceptable limit during this experiment.

Welding was performed in a semi-automatic KMPI make welding machine, as shown in Figure 1(a). The schematic of welding joint configuration is given in Figure 1(b), and the schematic for continuous and pulse spray mode is given in Figure 1(c).
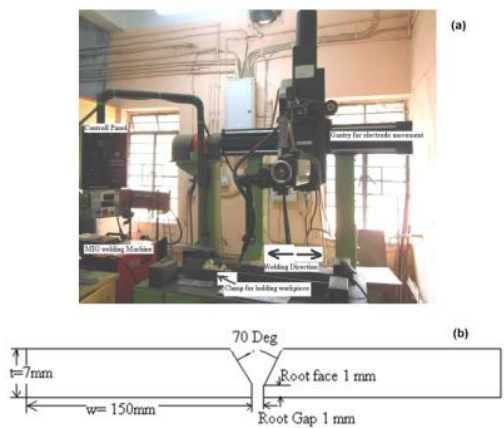

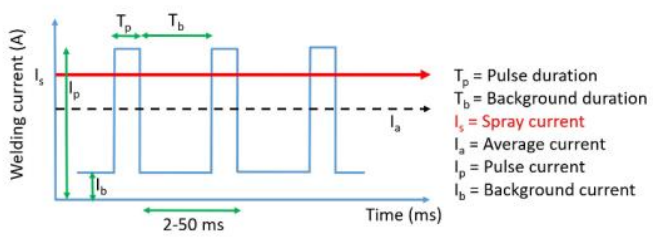

(c)

Fig. 1. (a) The welding equipment, (b) schematic for weld joint configuration and (c) continuous and pulse spray mode diagram.

\section{Tensile testing}

The tensile testing specimen was prepared as per ASME section IX standard from the welded specimen by machining. The geometry of tensile test specimens is shown in Figure 2. Tensile testing was carried out transverse to the welding direction in a 30T Instron make universal tensile testing machine with a crosshead speed of $5 \mathrm{~m} / \mathrm{min}$. The joint efficiency is defined as the ratio of weld joint strength to equivalent base metal strength:

Joint efficiency $(\%)=[$ UTS weld/UTS base $] \times 100$

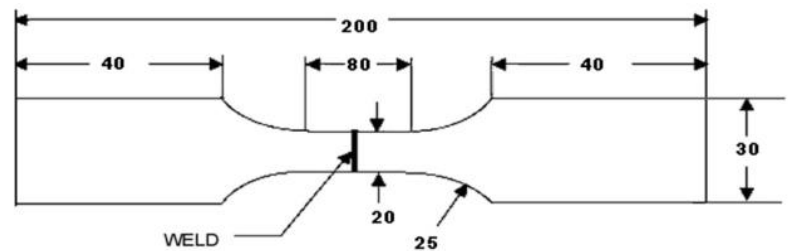

Fig. 2. The geometry of tensile test specimens.

Visual examination by dye penetration inspection

Visual examination of the weld joints was done to mark any weld defects (crack, void/underfill, pores, spatters, the extent of fusion, etc.). The weld surface was cleaned well and soaked with a liquid penetrant dye (Spotcheck SKD S2) for 30 minutes, and the change in colour was observed with a naked eye as well as under a stereo microscope (Dino Lite, AM4113T). 


\section{Microstructure}

Metallographic samples were collected from each welded sample. Cross sections of samples were polished and etched by $2 \%$ Nital solutions to reveal different micro structural features across the base, HAZ and weld. Microstructures were carried out in Olympus make PME3 optical microscope and JEOL make JSM6390 Scanning Electron Microscope.

\section{Microhardness}

The microhardness measurements were carried out by Vickers micro hardness tester at $100 \mathrm{gf}$ load for $20 \mathrm{~s}$ dwell time. Around 20 measurements were recorded and averaged out for better accuracy.

\section{Results and Discussions}

Visual inspection and cross-section macrostructures of weld joint

The weld appearances were shown in Figure 3. The joints were free from defects like porosity, undercut or lack of fusion. Few instances of spattering were observed in continuous spray mode. Visual observation of a cross section of weld joints after macroetching reveals the weld pool and HAZ. There was no significant difference among the two techniques (Spray \& Pulse-Spray) as well as 3 types of electrode wires during visual appearance examination. The HAZ micro structure consists of a lath type of martensite, which forms due to high cooling rate in this zone. No significant HAZ coarsening occurs adjacent to the weld HAZ interface, and thus almost all the samples fail from much away from the weld HAZ interface and failure occurs close to the base metal. The reason for no grain coarsening can be attributed to the stability of $\mathrm{Ti}-\mathrm{Nb}$ precipitates at high temperatures, including abundant grain boundary pinning by these fine precipitates $[6,8]$.

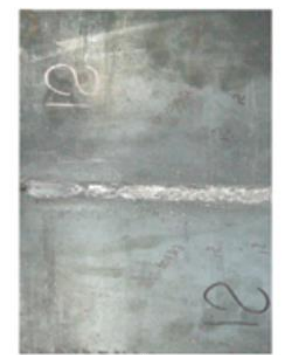

a)

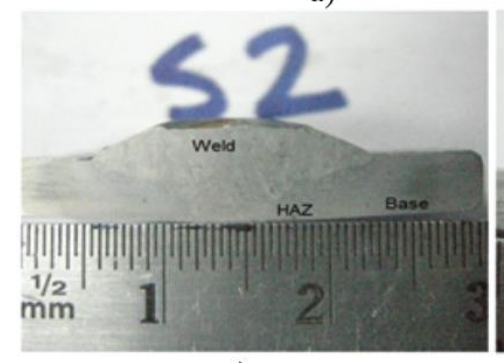

c)

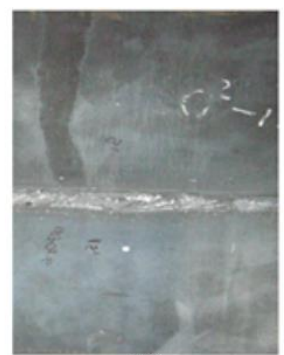

b)

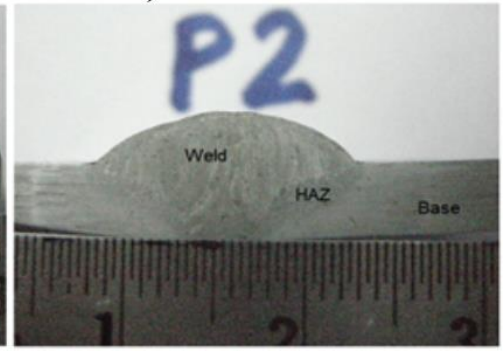

d)

Fig. 3. Weld joints: $(a, c)$ continuous spray mode; $(b, d)$ pulse spray mode. 
Compared to spray transfer mode, pulse-spray transfer combines high heat inputs of the spray transfer arc with slightly lower currents near the globular transfer range to provide a balanced average current low enough to allow for metal transfer in all positions, including flat region. The current is varied between a high and low value. Metal is only transferred to the work during the period of high current. Therefore, pulse-spray mode has less HAZ area in comparison to spray mode due to less heat input.

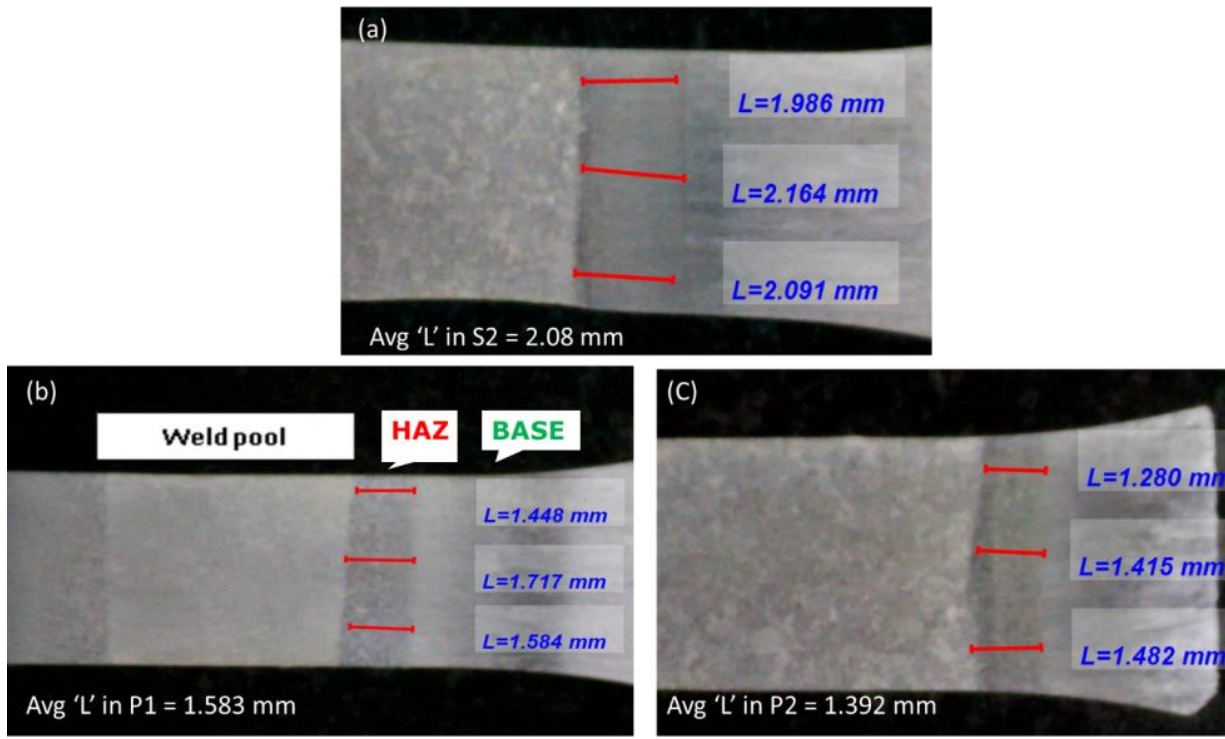

Fig. 4. Macrographs of weld joints of 3 samples - (a) S2, (b) P1, (c) P2.

Figure 4 shows the macrographs of P1, P2, and S2, the average HAZ width (L) is much lower in the pulse spray process (P1, P2) as compared to spray transfer to the process (S2). This is due to lower heat input in the pulse spray process $(1.05 \mathrm{~kJ} / \mathrm{mm})$ as compared to spray transfer process $(1.4 \mathrm{~kJ} / \mathrm{mm})$. Narrower HAZ width makes pulse spray a better choice over spray transfer mode [16]. However, no significant difference in HAZ width with respect to three filler wires is visible. This may be due to the fact that heat input $\&$ weld parameters are kept the same for all 3 wires.

\section{Microstructure of base metal}

Microstructures of base metal are shown in Figure 5. The base metal microstructure mainly consists of fine grain quasi polygonal ferrite (about 90\%) with traces of granular bainite (about 10\%). The ferrite grains are less than $5 \mu \mathrm{m}$ in size. Very fine grain size and presence of bainite along with fine Ti-Nb-C-N precipitates contributed to the very high strength of this UHSS steel. A study of similar Ti-Nb microalloyed hot rolled steel reveals that $\mathrm{Ti}-\mathrm{N}$ precipitates at higher temperature and $\mathrm{Ti}-\mathrm{Nb}$ carbides grow on it [6]. 

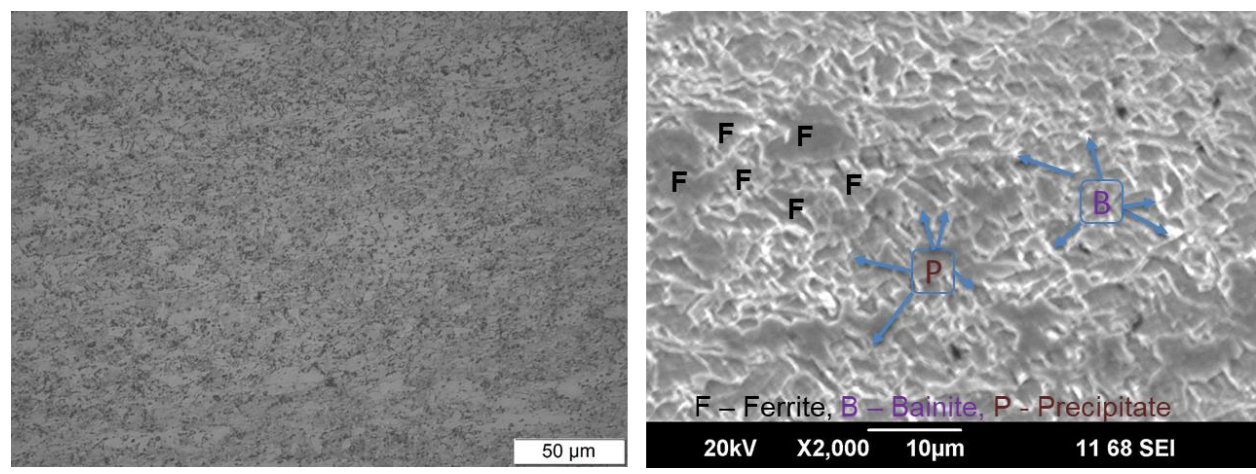

Fig. 5. (a) Optical micrograph, and (b) SEM Micrograph of base metal.

\section{Microstructure of Weld joints}

Microstructure samples from all six welds (S1, S2, S3, P1, P2, P3) have been examined by SEM in Base, HAZ, weld pool \& its interface area on both sides. The SEM micrographs of the weld pool of S1 \& P1 are shown in Figures 6 (c) and (d), respectively. It consists of coarse polygonal ferrite surrounded by acicular ferrite. Acicular ferrite is more resistant to crack propagation than bainite because of its mutual crisscross distribution and large angle grain boundaries [17]. The pattern resembles a dendritic solidification structure to some extent. Dendrites are finer in case of pulse spray, which is due to a smaller weld pool with less heat input $\&$ faster cooling rate. In case of pulse spray transfer mode, in weld pool dendrites reduce in size of electrode wire-3 over that in wire-2 and in wire-2 over that in wire-1. On comparison of microstructures and microhardness of the weld pool of spray weld samples-S1, S2 \& S3 also, similar observations are made. However, differences are less pronounced. This is obvious due to progressively higher alloy content and higher strength of filler wires from wire-1 to wire3 .

The microstructure of HAZ consists of a lath type of martensite, which forms due to a higher cooling rate in this zone. Moreover, this martensite is more of blocky type and less of strip type. Blocky martensite also resists cracking propagation [17]. No significant HAZ coarsening occurs adjacent to the weld/HAZ interface. The reason for no grain coarsening can be attributed to the stability of Ti-Nb-C-N precipitates at high temperature including abundant grain boundary pinning by these fine precipitates $[13,17,18]$. With each filler wire, martensite laths in case of pulse spray are more and finer in comparison to martensite in the case of spray transfer. It is because of faster cooling in case of pulse spray with less heat input.

On comparing HAZ microstructures P1, P2, and P3 (Figure 6 b, g, h), it appears that martensite laths are finer with higher strength of filler wire also to some extent. Quick heating followed by fast cooling in HAZ can cause localised austenite formation with subsequent partial transformation to martensite. 

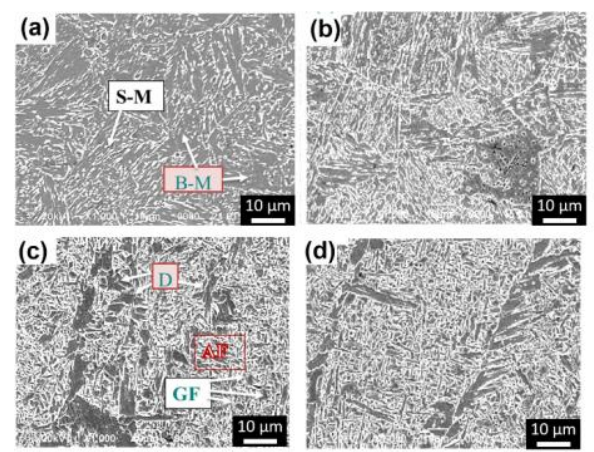
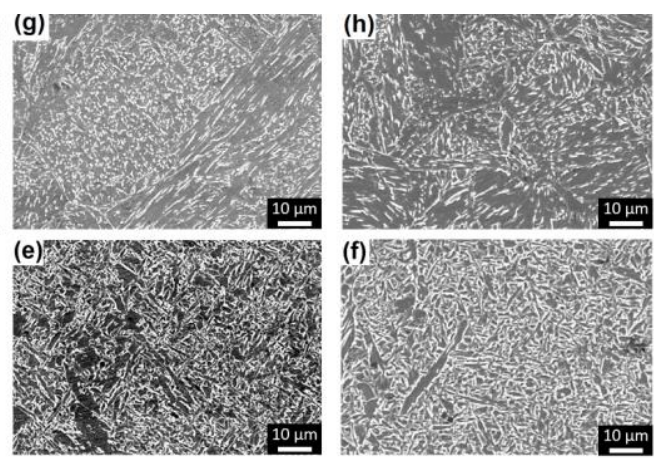

Fig. 6. SEM micrographs of HAZ: (a)-S1,(b)-P1,(g)-P2,(h)-P3; Weld Pool: (c)-S1, (d)-P1,(e)-P2,(f)-P3 (S-M = Strip Martensite, B-M = Blocky Martensite; $G F=$ Globular Ferrite, $A F=$ Acicular Ferrite; $D=$ Dendrite).

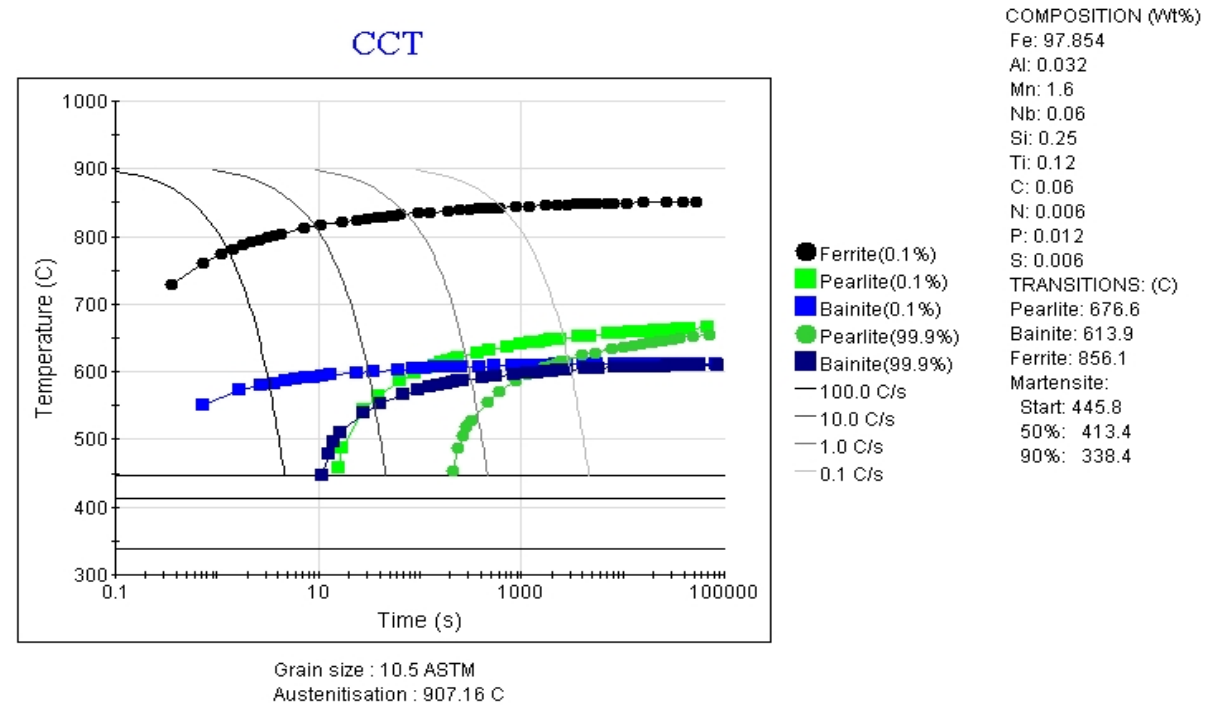

Fig. 7. Continuous cooling transformation (CCT) curve of base steel.

A commercial software JMatPro was used for simulating the continuous cooling transformation (CCT) curve (Figure 7) of the base steel. The CCT curve obtained through JMatPro for the chemistry of base steel shows the possibility of martensite formation in the HAZ. Finer martensite laths are responsible for slight increase in hardness from P1 to P2 \& from P2 to P3 in weld pool \& HAZ (Figure 7). Similar observations are made upon comparing the microstructures and microhardness of HAZ of spray weld samples - S1, S2 and S3. However, the differences are less pronounced. 


\section{Microhardness}

Figure 8 shows the micro hardness profile of the weld made on SM650 using three different filler wires and two different metal transfer modes (S1, S2, S3; P1, P2, P3). The hardness profile is taken from one side of the base metal to the other side of the base metal through HAZ and Weld bead. Hardness transverse indicates that there is no HAZ softening, rather hardness in HAZ is higher than base metal.
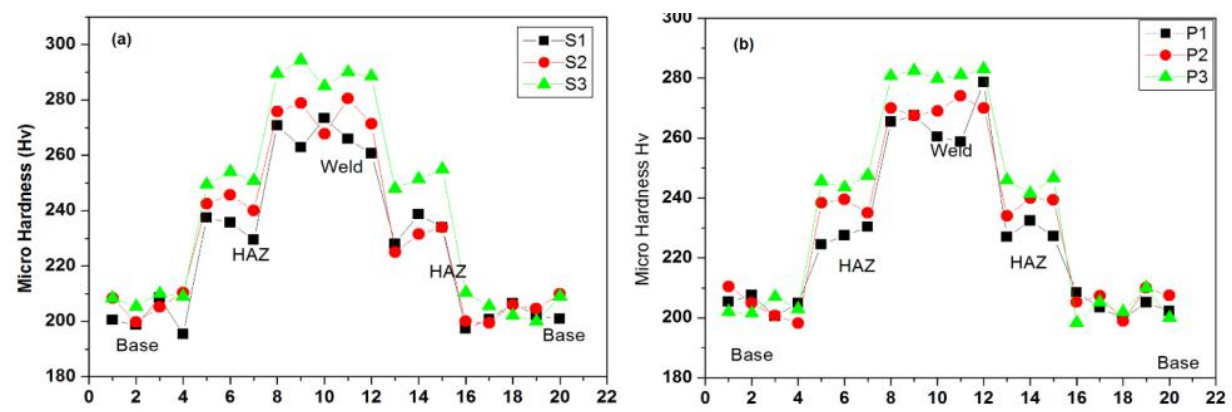

Fig. 8. Micro-hardness profile for (a) continuous spray mode, and (b) pulse spray mode.

Hardness in the weld pool and HAZ are found to be little higher for a higher strength of filler wire. Absence of HAZ softening not only validates the right choice of welding process \& parameter, but also indicates good weldability of the experimental steel. An earlier study reported a similar observation in HAZ of fusion welded ultra-fine grain heat treated HSLA steel with YS about $650 \mathrm{MPa}$ [19]. Hardness drop in HAZ increases with higher heat input \& a lower cooling rate, as observed in a simulation experiment of weld joints of Ti-Nb micro-alloyed S700MC grade steel [20]. In another study on weldability of similar Nb-Ti micro-alloyed hot rolled S700MC grade steel, hardness in HAZ was found to be lower by about 40-50 HV than base steel [17]. In this study, base steel has martensite also in addition to bainite. During welding the peak temperature in HAZ may be too low to cause ferrite-austenite transformation but high enough to temper the martensite present in base steel leading to softening [21]. Hardness in weld pool \& HAZ are higher for higher strength of filler wire in the same order. Hardness with wire $-3>$ Hardness with wire $-2>$ Hardness with wire -1 . But the hardness in HAZ in spray transfer was expected to be less due to high heat input as compared to pulse spray transfer. But this is not reflected in current results and more study is required in this context.

\section{Tensile testing}

The tensile properties of the GMA welded SM650 grade steel are given in Table 4. Three samples were tested from each set of base and weld steel. In most of the cases, specimens fractured in base steel / base-HAZ interface, much away from weld pool and HAZ (Figure 9). This is likely to be due to the absence of HAZ softening (Figure 8). 
Table 4. Tensile testing result.

\begin{tabular}{|c|c|c|c|c|c|c|}
\hline $\begin{array}{l}\text { Sample } \\
\text { ID }\end{array}$ & $\begin{array}{l}\text { UTS } \\
(\mathrm{MPa})\end{array}$ & $\begin{array}{l}\text { Average } \\
(\mathrm{MPa})\end{array}$ & UTS & $\begin{array}{l}\% \\
\mathrm{El}\end{array}$ & $\begin{array}{l}\text { Average } \% \\
\text { EI }\end{array}$ & $\begin{array}{l}\text { Joint efficiency } \\
(\%)\end{array}$ \\
\hline S1-1 & 704 & 695 & & 15 & 15 & 92.7 \\
\hline $\mathrm{S} 1-2$ & 698 & & & 16 & & \\
\hline $\mathrm{S} 1-3$ & 684 & & & 15 & & \\
\hline S2-1 & 715 & 700 & & 13 & 14 & 93.3 \\
\hline S2-2 & 696 & & & 14 & & \\
\hline S2-3 & 688 & & & 15 & & \\
\hline S3-1 & 718 & 703 & & 11 & 10 & 93.7 \\
\hline S3-2 & 690 & & & 10 & & \\
\hline S3-3 & 701 & & & 10 & & \\
\hline P1-1 & 730 & 720 & & 13 & 12 & 96 \\
\hline P1-2 & 718 & & & 11 & & \\
\hline $\mathrm{P} 1-3$ & 712 & & & 11 & & \\
\hline P2-1 & 675 & 690 & & 10 & 11 & 92 \\
\hline P2-2 & 700 & & & 11 & & \\
\hline P2-3 & 695 & & & 11 & & \\
\hline P3-1 & 718 & 711 & & 8 & 8 & 94.8 \\
\hline P3-2 & 700 & & & 8 & & \\
\hline P3-3 & 715 & & & 9 & & \\
\hline Base-1 & 760 & 750 & & 20 & 20 & NA \\
\hline Base-2 & 735 & & & 19 & & \\
\hline Base-3 & 755 & & & 20 & & \\
\hline
\end{tabular}

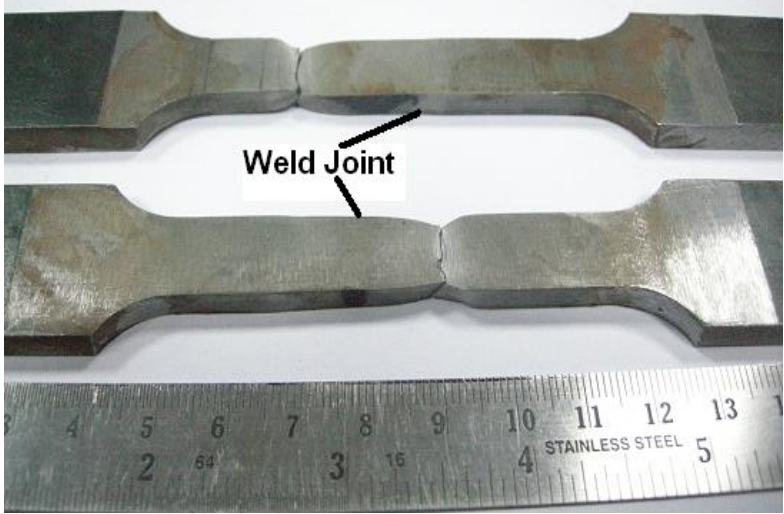

Fig. 9. Photograph of 2 weld samples with fracture after tensile test.

The joint efficiency is more than $90 \%$ in all cases, which is well accepted for welded joints [22]. The weld joint is free from external \& internal weld defects as observed by physical inspection, DP test \& macro-etching. Fine microstructural components in the weld pool as well as HAZ are favorable for good tensile strength \& fracture toughness [23, 24]. Due to lower HAZ width and favorable microstructural components (thinner \& less dendrite in weld pool and finer \& more martensite in HAZ), tensile strength of Pulse spray samples is expected to be higher - which is visible for S1 
vs P1 \& S3 vs P3. Similarly, favorable microstructure in the weld and HAZ area with higher strength electrodes is reflected some extent in increasing UTS of S-series weld samples. However, it appears more tensile testing of weld samples may need to be performed in order to establish a correlation with its microstructure.

Control of heat input and selection of proper filler is very critical in welding. The HAZ is the part of the base metal that is heated to a high temperature (near the melting point) but not melted. The HAZ size and its hardness are controlled by the heat input. The higher the heat input, the larger will be HAZ width due to lower cooling rate. This may lead to hardness lower than base metal in extreme cases. Also, during welding and subsequent cooling process, HAZ grains closer to the weld pool tend to coarsen; whereas HAZ grains close to the base steel remain unchanged. In welded structures, the HAZ is the weakest link and thus a very narrow HAZ is typically desirable [25, 26].

\section{Conclusions}

All weld joints are free from any defects like porosities, undercut or lack of fusion and of acceptable quality. No tensile samples failed at the weld joint or in the Heat Affected Zone (HAZ). All samples failed at the base or at the base-HAZ interface indicating strong welding. Ultimate Tensile Strength (UTS) of weld samples greater than $90 \%$ of the base metal also shows well accepted weld joint efficiency. Although both welding processes are suitable, the pulse spray process is better in comparison to the spray process on account of higher weld joint efficiency and lower HAZ width. HAZ being the usual weakest zone in welding, the lower is its width the better is the welding. HAZ width is lower in case of pulse spray due to lower heat input. Analysis of microstructure and microhardness data shows that there is no HAZ softening. Moreover, microstructural constituents with respect to phase, size and precipitates are resistant to softening and crack propagation. Hence the material is weldable even with normal ER70S-6 (type-1) electrodes without any specific requirements of pre or post weld heat treatment. Filler metal strength did not affect the tensile properties of the butt joints welds of S650MC significantly. However, higher strength filler wire (ER100SG, YS 690, type-3) may be chosen as per standard welding practice.

\section{Acknowledgements}

The authors are grateful to the management of JSW Steel, Dolvi, for necessary support in carrying out this study. Facilities provided by the Welding Technology Centre, Department of Metallurgical and Materials Engineering, Jadavpur University is also highly appreciated. Authors are also thankful to the Global R\&D Centre of M/S Crompton Greaves for providing their testing facilities.

\section{References}

[1] R. Wadhera, "White Paper on Alternative Fuels for Vehicles - Vision \& Recommendations, Alternative Fuels in India", https://www.siam.in/uploads/ filemanager/159SIAMWhitePaperonAlternativeFuelsforvehicles.pdf Accessed 10 September 2021.

[2] A. Mascarin, T.Hannibal, A.Raghunathan, Z.Ivanic, M.Clark, "Vehicle Light weighting: Mass Reduction Spectrum Analysis and Process Cost Modelling" (Report Number: INL/EXT-16-38001), https://www.osti.gov/servlets/purl/ 1363637 Accessed 10 September 2021. 
[3] S. Kumar, M. Singhai, R. Desai, S. Sam, P.K. Patra: J Inst Eng (India): Ser. D, 97 (2016) 153-158.

[4] D. Raabe, et al.: Metall Mater Trans A, 51 (2020) 5517-5586.

[5] World Steel Association AISBL, "Home - AHSS Guidelines", https://ahssinsights.org/ Accessed 10 September 2021.

[6] M.H. Safa, R. Ramadan, S. Ibrahim: J Pet Min Eng, 19 (2017) 71-80.

[7] K. Sugimoto; S.Sato, J.Kobayashi, A.K. Srivastava: Metals, 9 (2019), 1066.

[8] L. Bejar-Gomez, A. Medina-Flores, H. Carreon, I. Alfonso, J. Bernal-Ponce, J.A. Ascencio: Revista mexicana de física, 55 (2009) 110-113.

[9] A.K. Srivastava, A. Sharma: Am J Mater Eng Technol, 5 (2017) 7-13.

[10] F. Javidan, A. Heidarpour, X-L. Zhao, C.R. Hutchinson, J. Minkkinen: Eng Struct, 118c(2016) 16-27.

[11] P. Zhai, S. Xue, J. Wang, W. Chen, T. Chen, S. Ji: Metals, 10c(2020) 665.

[12] S. Das, J. Vora, V. Patel, S. Bogum: J Phys: Conf Ser, 1950 (2021) 012043.

[13] B. de Meester: ISIJ Int, 37 (1997) 537-551.

[14] H. Wang: Mater Trans, 46 (2005) 593-601.

[15] Welding Answers, "How To Calculate Heat Input From Welding": https://weldinganswers.com/how-to-calculate-heat-input/ Accessed 10 September 2021.

[16] P. Kah, M. Pirinen, R. Suoranta, J. Matikainen: Adv Mater Res, 849 (2014) 357365.

[17] X. N. Wang, H.S. Di, C. Zhang, L.X. Du, X.X. Dong: J Iron Steel Res Int, 2012 19:6 (2012) 64-69.

[18] M. Maalekian, ASM Handbook, Volume 6A: Welding Fundamentals and Processes, first ed., ASM International, Ohio, 2011, 122-137.

[19] P.J. Modenesi, R.F. Fajardo, D.B. Santos: Mater Sci Forum, 638-642 (2010) 3704-3709.

[20] J. Gorka: MTAEC9, 50(4) (2016) 617-621.

[21] M.D. Tumuluru, ASM Handbook, Volume 6A: Welding Fundamentals and Processes, first ed., ASM International, Ohio, 2011, 409-422.

[22] C.D. Sorensen, ASM Handbook, Volume 6A: Welding Fundamentals and Processes, first ed., ASM International, Ohio, 2011, 664-677.

[23] G. Meschut, V. Janzen, T. Olfermann: J Mater Eng Perform, 23 (2014) 15151523.

[24] R.W. Messler Jr., ASM Handbook, Volume 6A: Welding Fundamentals and Processes, first ed., ASM International, Ohio, 2011, 16-21.

[25] C. Conrardy, ASM Handbook, Volume 6A: Welding Fundamentals and Processes, first ed., ASM International, Ohio, 2011, 309-320.

[26] U.K. Ghosh, Design of Welded Steel Structures: Principles and Practice; first ed., CRC Press: London/New York, 2016, 16-22.

\section{(c) (†) Creative Commons License}

This work is licensed under a Creative Commons Attribution 4.0 International License. 